\title{
Multiple Congenital Bilateral Trigger Digits in a 2-Year-Old Child: Case Report
}

\author{
V. De Luna, V. Potenza*, L. Garro, P. Farsetti and R. Caterini
}

Department of Orthopaedic Surgery, University of Rome Tor Vergata, Rome, Italy

\begin{abstract}
Trigger finger is a rare condition in children. In this paper, we report on a 2-year-old boy with multiple congenital bilateral trigger digits. The patient had no history of perinatal trauma, viral or bacterial infections, or metabolic disorders. The patient was treated with physiotherapy for one year. At the one-year follow-up, the boy presented with six trigger fingers ( 3 on the right hand, 3 on the left hand). Neither thumb was involved. The six trigger fingers were treated surgically: first, the right-hand trigger fingers and, six months later, those of the left hand. After each operation, a 4-week brace in extension was applied to the operated hand. The symptoms were completely resolved after surgical treatment. Many authors have recommended surgical release for the treatment of trigger finger in children; empirical treatment with physiotherapy may be an option when symptoms present or appear at an older age.
\end{abstract}

Keywords: Trigger digits, congenital, children, bilateral trigger fingers, metacarpophalangeal joint, surgical treatment.

\section{INTRODUCTION}

While trigger thumb in the pediatric population is a common pathological condition [1-4], trigger finger is rare. Furthermore, multiple congenital bilateral trigger finger in children is an extremely rare condition [5-7], sometimes associated to genetic disorders $[8,9]$. Conservative treatment is recommended for six months to two years, according to the age of the patient. Surgical treatment is indicated after three year of age [1-3]. The most common non operative treatments performed are passive flexion-extension stretching of the fingers and splint therapy. In this study, we report on a very rare condition of multiple congenital bilateral trigger finger in a 2-year-old child, treated surgically at our Department.

\section{CASE REPORT}

A 2-year-old boy was seen with a complaint of triggering in the fingers of both hands. His mother stated that triggering had been noticed at birth in all the boy's fingers. There was no history of perinatal trauma, viral or bacterial infections, or rheumatologic or metabolic disorders, and the boy's development had been normal without any other anomaly.

At presentation, the physical examination showed painless nodules that could be palpated on the metacarpophalangeal joints of all fingers of both hands. Triggering was constant in all fingers; a snap was evident on flexion to $60^{\circ}$. Active flexion of the distal joint was not possible. Pain was associated with the triggering. Radiographs of both hands were normal.

The patient was treated with physiotherapy and passive home exercises of finger flexion/extension done by his mother. Physical therapy consists of passive flexionextension stretching of the involved fingers. At the one-year

*Address correspondence to this author at the Policlinico Tor Vergata, Viale Oxford, 81, 00133, Roma, Italy; Tel: +39 06.2090.3466;

E-mail: vitopotenza2@virgilio.it follow-up, the patient presented with six trigger fingers: 3 fingers of the right hand (index, middle and ring fingers) and 3 of the left hand (middle, ring and little fingers); his thumbs were not involved in the disease. The boy was 3 years old, and surgery was decided.

The boy was treated surgically by a transverse incision in his right palm and release of the A1 pulleys of the index, middle and ring fingers (Fig. 1). The tendons appeared to be slightly roughened on the surface; a mild tendon sheath thickening was described, and some adhesions with superficial and deeper layers were found. After the operation, good joint motion was obtained for each digit without triggering. The patient was protected with an

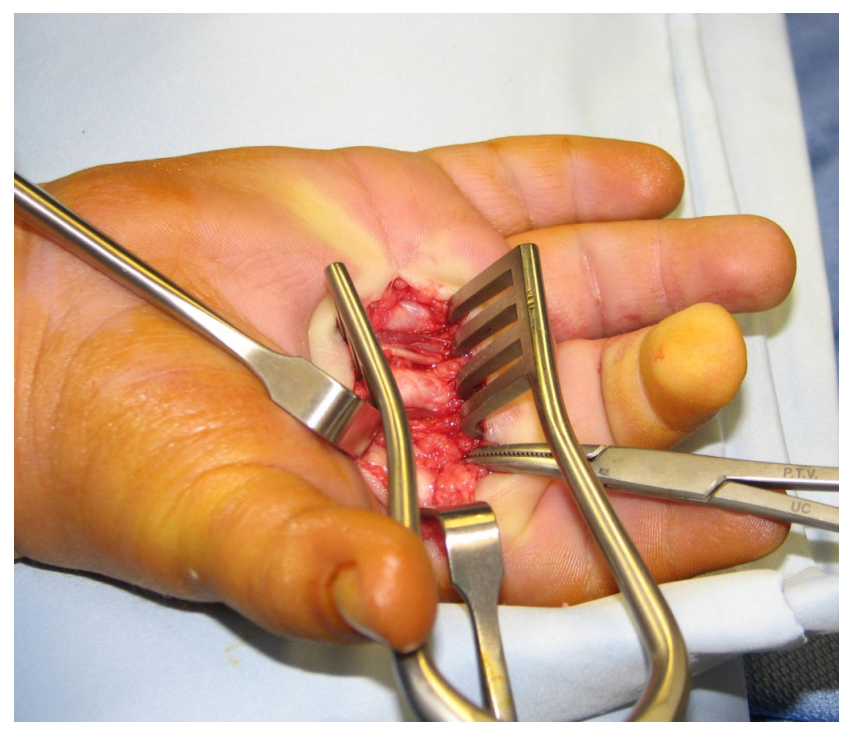

Fig. (1). Surgical procedure on the right hand: transverse incision in the palm and release of the A 1 pulleys of the index, middle and ring fingers. 
antibrachium-metacarpal brace positioned with his fingers in extension for 4 weeks. At the one-month outpatient followup, the brace was removed and the patient was able to flex and extend his fingers without triggering (Fig. 2).

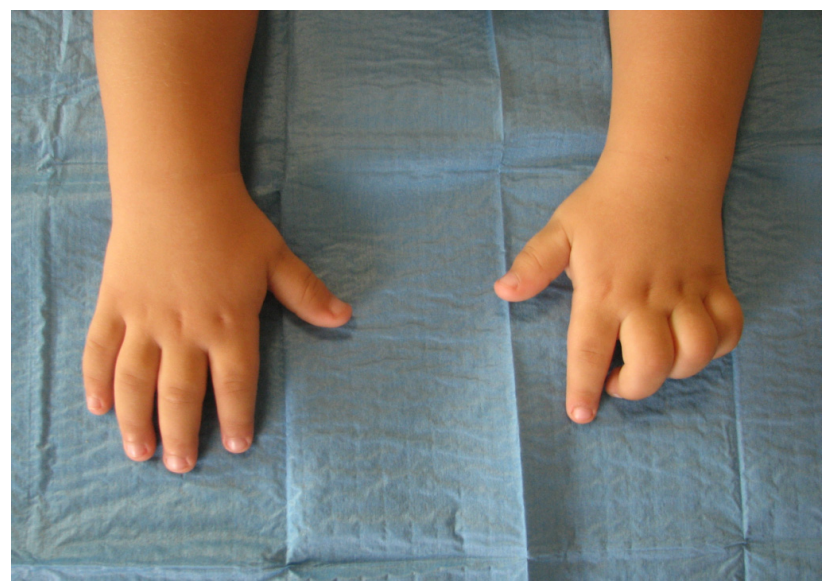

Fig. (2). One month after the operation on the right hand. Full extension of the operated fingers was present. At that time, the left hand showed trigger digits in the middle, ring and little fingers.

Six months after the first operation, the middle, ring and little fingers of the left hand were treated surgically with the same procedure (Fig. 3). Post-surgery care was the same as that of the right hand. At the one-month outpatient followup, the left-hand fingers were also able to flex and extend without triggering and/or pain.

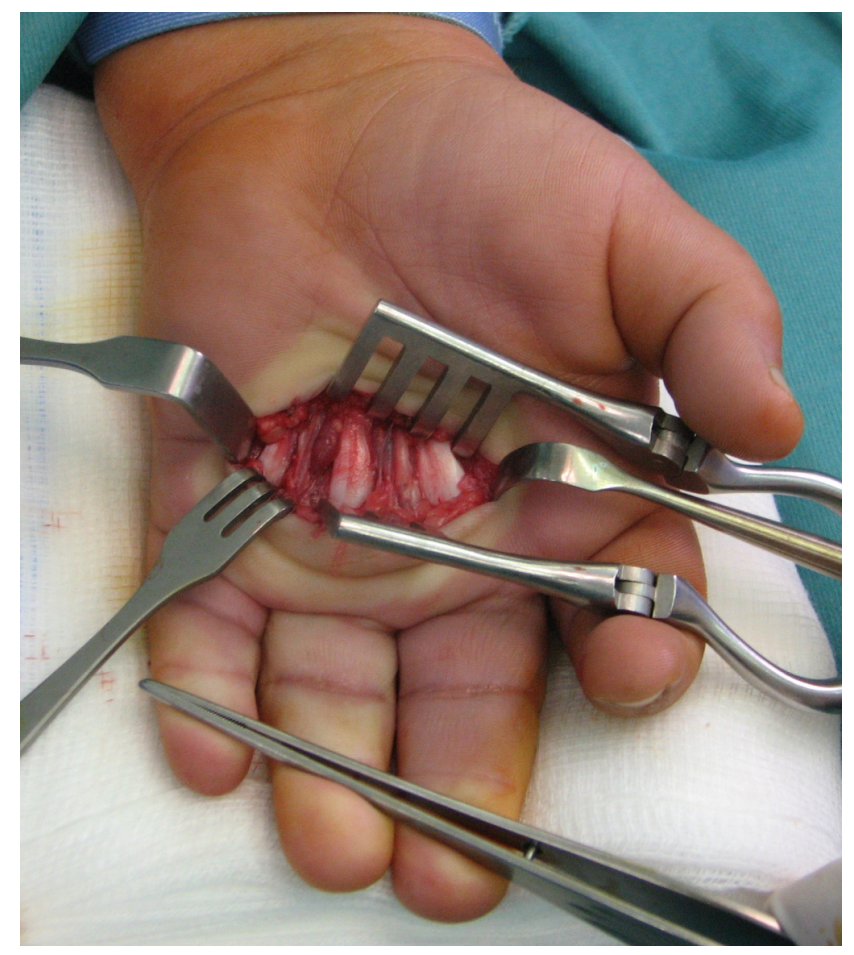

Fig. (3). Surgical procedure on the left hand: transverse incision in the palm and release of the A1 pulleys of the middle, ring and little fingers.
At the final follow-up, one year after the second surgical procedure, the patient could move all his fingers of both hands without triggering or pain.

\section{DISCUSSION}

Trigger digits in children, other than thumbs, are rare. Multiple bilateral finger involvement is an extremely rare condition [5-8]. It has been suggested that the aetiology of trigger finger is genetic $[2,8]$, but other aetiologic factors have been proposed for the development of this pathological condition [10]. If this pathological condition is left untreated may cause a significant disability of the hand.

In children, sometimes, digits do not trigger, but remain locked in the flexed position [3,10]. In our case, triggering was present in all fingers.

There is still controversy as to whether the congenital trigger digit is a congenital or an early acquired condition. One study reported that the mean age at onset of trigger finger in children is 11 months (range: birth to 3 years) [11]. In our case, his parents claimed that all 8 trigger fingers were present at birth.

Dinham and Meggitt [10] found that in $12 \%$ of their pediatric patients trigger thumbs healed spontaneously within a period of six months. De Smet et al. [12] and Tordai and Engkvist [13] reported some cases of trigger fingers in children in whom the problem was resolved without an operation. Pargali and Habibzadeh [7] reported on a very rare condition of bilateral trigger finger in a 5-year-old child which resolved completely with physiotherapy (eight sessions) and non-steroidal anti-inflammatory drugs (NSAIDs) for 20 days.

Most authors recommend surgical treatment, particularly if trigger finger persists after conservative treatment $[2,11$, $12,14-16]$. Section of the A1 pulley of the flexor tendon is the most common surgical treatment performed for trigger finger, but the timing of surgery is still debated $[3,12]$. Moutet et al. [5] described a case of a 3-year-old girl affected by ten congenital trigger fingers. The girl was treated surgically by a transverse incision in both palms and release of all A1 pulleys. The authors reported that the final result was good. Oda et al. [6] described a case of a 9-yearold boy treated for multiple congenital bilateral trigger digits in addition to the thumb. Triggering was most constant in the middle and ring fingers and observed only occasionally in the index and little fingers. Surgical treatment was performed only on both middle and ring fingers. Good joint motion without triggering was reported after surgical release of the pulleys.

In our case, notwithstanding conservative treatment, the pathological condition persisted in six fingers. The symptoms were completely resolved after surgical treatment.

In conclusion we believe that in multiple trigger fingers surgical treatment is indicated in all cases in which conservative treatment failed.

\section{CONFLICT OF INTEREST}

The authors confirm that this article content has no conflict of interest. 


\section{ACKNOWLEDGEMENTS}

Declared none.

\section{REFERENCES}

[1] Sprecher EE. Trigger thumb in infants. J Bone Joint Surg Am 1949; 31A(3): 672-4.

[2] Fahey JJ, Bollinger JA. Trigger-finger in adults and children. J Bone Joint Surg Am 1954; 36-A(6): 1200-18

[3] Wood VE, Sicilia M. Congenital trigger digit. Clin Orthop Relat Res 1992; (285): 205-9.

[4] Sevencan A, Inan U, Köse N, Omeroğlu H, Seber S. Percutaneous release for trigger thumbs in children: improvements of the technique and results of 31 thumbs. J Pediatr Orthop 2010; 30(7): 705-9.

[5] Moutet F, Lebrun C, Sartorius C. 10 congenital trigger fingers. Apropos of a case report. Ann Chir Main 1987; 6(4): 299-302.

[6] Oda Y, Uchida Y, Kojima T, Sugioka Y. Congenital, multiple, bilateral, trigger digits in a child. Int Orthop 1993; 17(1): 20-2.

[7] Pargali N, Habibzadeh F. Bilateral trigger finger in a 5-year-old child: case report. J Plast Reconstr Aesthet Surg 2011; 64(11): e283-4.
[8] Thomas SRYW, Dodds RDA. Bilateral trigger thumbs in identical twins. J Pediatr Orthop B 1999; 8: 59-60

[9] Vyas BK, Sarwahi V. Bilateral congenital trigger thumb: role of heredity. Indian J Pediatr 1999; 66: 949-51.

[10] Dellon AL, Hansen FC. Bilateral inability to grasp due to multiple (ten) congenital trigger fingers. J Hand Surg Am 1980; 5(5): 470-2.

[11] Sharma PR, Gore SM, Schreuder FB. Bilateral trigger finger in a 7 year-old after a viral infection: case report. J Hand Surg Am 2010; 35: 1334-5.

[12] Dinham JM, Meggitt BF. Trigger thumbs in children. A review of the natural history and indications for treatment in 105 patients. $\mathrm{J}$ Bone Joint Surg Br 1974; 56(1): 153-5.

[13] Cardon LJ, Ezaki M, Carter PR. Trigger finger in children. J Hand Surg Am 1999; 24(6): 1156-61.

[14] De Smet L, Steenwerckx A, Van Ransbeeck H. The so-called congenital trigger digit: further experience. Acta Orthop Belg 1998; 64(3): 306-8

[15] Tordai P, Engkvist O. Trigger fingers in children. J Hand Surg Am 1999; 24(6): 1162-5.

[16] Wilson DH. Tenosynovitis, tendovaginitis and trigger finger. Physiotherapy 1983; 69(10): 350-2.

(C) De Luna et al.; Licensee Bentham Open.

This is an open access article licensed under the terms of the Creative Commons Attribution Non-Commercial License (http://creativecommons.org/licenses/by-nc/3.0/) which permits unrestricted, non-commercial use, distribution and reproduction in any medium, provided the work is properly cited. 